\title{
Naughty Realism: The Britishness of British Hardcore R18s
}

I.Q. Hunter

Hardcore pornography may be a film genre, but it is by no means an ordinary one (Williams 1991). Quite apart from its uses and affects, which are arguably at odds with those of narrative cinema, hardcore remains an outlaw genre, toxic and degrading, rigorously policed and segregated, and universally reviled. It often seems to be a genre without an audience, for people rarely admit to watching hardcore films - the standard term is 'using', as with drugs - and thereby admitting to masturbation, which remains, for men at least, a rare surviving sexual taboo.

Nevertheless, porn does appear to be a popular genre. Trustworthy figures about sales, internet traffic and usage are hard to come by (Chalabi 2013). Most statistics relate to accessing porn on the internet, but their accuracy is controversial and they are cited to scare as much as to inform (Ministry of Truth 2013). One much cited survey from 2012 claims that a third of all internet usage is porn-related (Anthony 2012). An older survey, from 2006, put the UK as ranking sixth among nations in terms of pornography revenue (\$1.97 billion), behind the table leader, China ( $\$ 27.40$ billion), South Korea, Japan, the US (\$13.33 billion), and Australia (Ropelato 2006). US porn revenue, the survey noted, exceeded the combined revenues of $\mathrm{ABC}$, CBS, and NBC. Another survey claimed that Britain was the fastest growing market for internet porn, and, in Britain, women the fastest growing demographic (Hayes 2006). Whatever the validity of these statistics, they underline that hardcore porn is an immensely successful phenomenon even as it becomes an object of increasing social and cultural unease. Rather than the addiction of a dangerous and 
perverse minority, porn is a leisure activity of a large and varied percentage of the British population.

In Britain till the 1980s hardcore pornographic films - explicit depictions of non-simulated sexual activity - were difficult to see beyond a handful of cinema clubs and illegal, expensively purchased 8mm films or 'rollers'. A clandestine market did exist in the 1960s and 1970s, aided by pay offs to corrupt police in the Obscene Publications Squad, and British filmmakers such as Mike Freeman and John Lindsay made short ‘blue movies’ shown in sex cinemas (Hunter 2013: 115 - 9). During the video boom of the early 1980s uncensored tapes were available by mail order till the 1984 Video Recordings Act, brought in to regulate 'Video Nasties', closed this legal loophole. Hardcore remained illegal in the 1990s but an underground market thrived for dubbed videos and recordings of foreign satellite stations, which were passed around among friends or supplied 'under the counter' in regular video shops.

In 2000 hardcore finally became legal for sale on video and later DVD, but only in licensed 'sex shops', where they share floor space with sex toys, bondage equipment, magazines, and poppers. The videos must be issued with an R18 certificate from the British Board of Film Classification, which now passes between 800 and 1200 R18 DVDs a year and cuts roughly a quarter of them. Although most of the films are from the United States, there is a good deal of British hardcore production and a number of companies and labels that brand themselves as 'British', such as Harmony (which also releases US films and runs a chain of comparatively upmarket and female-friendly sex shops), Rude Britannia, Union Films, Viv Thomas (now based in Portugal), Pumpkin Films and the avant-garde Tanya Hyde. This article offers an admittedly impressionistic snapshot of the British porn films available at R18, particular those of 'auteurs' such as Ben Dover (Lindsay Honey) 
and Anna Span (Anna Arrowsmith), and tentatively unpicks their distinctively 'British’ style of legally sanctioned hardcore. ${ }^{1}$

\section{R18s}

The R18 certificate was introduced in 1982 following the recommendations of the Williams Committee report in 1979. This allowed for stronger films to be available for cinema clubs and on video, but only in licensed sex shops and not distributed by post. However the R18s were scarcely more explicit than 18-rated softcore and it wasn’t until 1997 that the British Board of Film Classification experimented with passing non-simulated sex, albeit only in medium and long shot. In September 2000 a judicial review sought by the BBFC, bizarrely enough against its own Video Appeals Committee (VAC), upheld the VAC’s 1999 ruling that certificates should not have been refused to seven explicit porn films (Petley 2000). The BBFC revised its guidelines and effectively legalised the sale of hardcore in licensed sex shops. R18s can still neither be sent through domestic post nor shown on British satellite channels such as Television $\mathrm{X}$, though hardcore is available on related web sites such as Televisionx.com, and the films can be streamed online beyond the control of the BBFC.

The BBFC categorises hardcore porn as 'sex works' intended for sexual arousal, and enforces a division between films with art house credentials, which can include brief real sex, and those apparently designed for the single purpose of facilitating masturbation. Explicit real sex is passed at 18 rather than R18 by the BBFC only if 'justified by context' - in other words, serious intention - or by an educational purpose (one of the first was a British instructional sex video, The Lover's Guide (1991)). The films passed, with a few exceptions such as Caligula (1979), 
have tended to be art house movies, from re-released classics such as In the Realm of the Senses to Lars Von Trier's The Idiots (1998) and the 'New French Extremity'Romance (1999), Baise Moi (2000), and Anatomy of Hell (2004), and two British ‘artcore’ entries, Intimacy (2001) and 9 Songs (2004).

The censors came up with a check list of permitted and, more important to distributors, banned acts at R18, such as fisting, heavy BDSM (bondage, domination and sado-masochism, more or less) and 'urolagnia' (urination during sexual activity; the sight of urination itself is not banned). The BBFC cuts films at R18 not only according to its guidelines and to protect distributors from various pieces of legislation such as the Obscene Publications Acts 1959 and 1964, but also, as Julian Petley has shown, on the grounds of good taste (Petley 2013). The BBFC intervenes heavily in the R18 category: in 2010, for example, of the 802 DVDs classified at R18 123 were cut. Cuts are usually to violence beyond mild BDSM, specifically prohibited acts such as urolagnia, and imitable and potentially dangerous trends in porn such as gagging, restricted breathing, and the vaginal or anal insertion of large objects.

Making sense of the R18s displayed in sex shops is frankly bewildering unless one has unlimited time and considerable resources. The typical price for an R18 DVD in a sex shop such as Harmony or Strictly Pleasure is $£ 25$ new (or three for $£ 50$ ), which even now confers an aura of exclusivity upon them (an exchange system is usually available, however). Covering all of the ‘British’ films would be a lifetime’s work even for a hardcore - in every sense - completist; and I cannot pretend to have seen more than a few dozen of the DVDs for which 'British' is regarded as a selling point as much as a label of provenance.

Although porn is conventionally said to be all the same, contemporary porn production has splintered into ever more numerous sub-genres catering to specialised 
interests. This is most evident online, where films and clips on porn sites such as Redtube are sorted by 'Category’ ('Anal', 'Cumshot', 'Ebony’ 'Teens') and content is flagged by user-generated tags. Some of these interests are broadly visible in sex shops' organisation of material. Straight and gay DVDs are shelved separately, for example, while other sections, by a casual Borgesian logic, divide up stock by theme, performer, or production company, so as to orientate the customer towards key brands and, most important, the newest products.

In a shop such as Simply Pleasure, one such discrete and promoted category is 'British'. This connotes not only British-based producers and their labels, but also a niche style of porn that purchasers might recognise and seek out. According to a 2006 BBFC report on pornography, British films have acquired a definite interest among porn audiences: 'US produced sex works are a clear favourite (40\% of respondents), followed by French and German produced works. British made sex works come fourth (11\% of respondents)' (BBFC 2006). How could there be anything especially 'British’ about porn, a cultural product notorious for its repetition and standardisation? Why rather than simply imitating more popular American products, should British porn find market advantage in self-classifying - from Ben Dover's British Cum Queens (2001), Relish’s Maid’s [sic] in Britain (2004) and Harmony’s Best of British (2008) compilation ('All British, All Filth’), to Union Films’s Dirty Asian Girls (2009) (tag-line, ‘Home Grown Asian Girls’).

A sense of what 'British' can mean is gained from the films' titles: Play the Slut (2008), Freddie's British Sluts 12 (2003), Hug a Hoodie (2011), and Dirty Birds: Great Britian's [sic] Dirtiest (2005). This is a world of downmarket 'real' porn, a seeming adjunct to a flourishing underground of enthusiastic amateurs and 'nice women who love to play dirty', as the tagline for Anna Span's Play the Slut puts it. 
On British porn sites, too, as in magazines like Escort and Razzle the key discursive terms are British slang linking sex with class - 'chavs', 'dogging', 'scrubbers', 'escorts', 'prozzies', 'missus', 'shagging', 'bonking', 'pegging', and above all 'sluts'. Sex and the women offering it - often 'real wives' and girlfriends - are presented as invitingly ‘dirty’. Misogyny and tastelessness combine to evoke a working class culture of sexual incontinence (and, perhaps, resistance to middle class restraint and hypocrisy) as well as subcultural entertainments such as dogging (sex in public places, especially car parks), swapping, punting, and stripping. The discourse is summed up by one site, www.topuksex.com, which, under the banner 'Never Mind the Bollocks Here's the Top UK Sex Sites', links to and reviews British online porn:

British porn has a style all of its own, it has a raw, amateur and hardcore edge that american [sic] porn lacks. Who wants to see plastic looking, over tanned, fake titted pornstars getting laid when you can see real teens and amateur sluts get hot and sweaty instead!

The impression is of small scale productions reflecting an active and enthusiastic culture of working class sex, which, as in sex comedies such as Personal Services (1987) and Channel Four's documentary, Dogging Tales (TX. 4 April 2013), is, for all its sexism, cosy rather than dangerous, democratic and 'a laugh'. This tends to back up Tim Fountain’s amusing vignettes of real life British doggers and swingers more obsessed with convenient parking than with getting their ends away - 'the quality of the sex on offer usually takes second place to the ease with which they can find it' (Fountain 2008: 242). Poppy Morgan, the porn actor and director, emphasises the importance of 'realism' as a contrast with the glamorous style of American porn: 
British films made by Harmony, Rude Britannia etc. are typically British. By that I mean they tend to be more 'real' and down to earth. With the majority of American companies, though not all, they tend to have more focus on extravagant wardrobe and make-up and high degrees of 'acting'. Some people like this style, some think it becomes too false and over the top. I tend to prefer the more natural style of shoot... I think for the viewer it is far more important to feel a connection with the actors, feel they could actually be their girlfriend or someone they know, rather than like a 'fantasy', a girl who is out of touch for them (personal communication 22 November 2011).

Variations on international trends such as XXX parody films similarly veer away from imitating mainstream gloss and find inspiration in television comedy and reality TV. Unlike US films such as Avatar XXX (2010) and The Dark Knight XXX: A Porn Parody (2012), Britain offers Little Fit 'Un (2008), a take-off of the Lou and Andy sketches in the comedy show, Little Britain; The Only Way is Sexsex (2011), which guys the reality TV show, The Only Way is Essex; To the Manor Porn 2 (2006), which riffs on but does not closely 'adapt' the TV comedy series, To The Manor Born; and Only Fools and Arses (2011).

British porn is positioned as an authentically ‘filthy' home grown alternative to fake American professionalism (though some American porn, especially Hustler, has also presented itself as a blue collar alternative to middle class good taste and the aspirational style of Playboy (Kipnis 1999)). Rather like mainstream British cinema, British porn is identified by its 'realism', grittiness, comedy and nostalgia. Continuities with the discourses of 1970s sexploitation films, such as Confessions of a 
Window Cleaner (1974), are striking. Leon Hunt makes this point about the class connotations of David Sullivan's ‘strong’ magazines such as Whitehouse in the 1970s: 'Sullivan's magazines hinted at the upward mobility of the aspiring pornocrat, but solicited an impatient working class "punter" who wanted the goods delivered at an aggressively lower price. The “Readers' Wives' ... grew out of this ethos’ (Hunt 1998: 130).

The emphasis on realism and local reference chimes with Susanna Paasonen’s description of 'Finnporn', recent Finnish porn films in which 'semi-amateurism, small budgets and homespun aesthetics' (2012: 179) address the audience with 'shared codes, recognition and familiarity that work to strengthen the films' claims of homespun authenticity and overall realism’ (2012: 190). British porn, by contrast, revolves around class and comedy, carving out a space for what might be called naughty realism. Its appeal, according to Lindsay Honey, is also simply that it is so unexpected given the sexual repressiveness of British culture. The overwhelming sense of 'naughtiness makes it different' (author interview 1 May 2012). As Honey explained, in a 1993 interview:

The problem is whether art can be erotic. You can look at these upmarket sets and you ask, 'Is it horny?' And I just don't think it is. Do you think sex is dirty? No? Then you're obviously not doing it right. You've got one of these pictures with some gorgeous girl dressed in some Renaissance uniform and it's all very beautiful, and then you look at Escort with some little nineteen-yearold flashing her arse up the stairs of a bus or something with her knickers pulled right up into her pussy, and you think, 'Cor, fuckin’ hell.’ It’s just 
instant turn-on. The other stuff is too far removed. This one might happen, the other never would. It’s more real (Honey in Green 1993: 197).

The films unquestionably profit from negative stereotypes of working class women as worthless 'slags' - only in liberal fantasy is pornography a progressively transgressive genre - but they are fetishised and celebrated as rude expressions of a traditionally unruly Britishness.

In Office Sluts 2 (2006), for example, released by Rude Britannia, the ordinariness of the setting, a typical porn scenario of casually set-up bouts in offices, is enhanced by the working class accents and bodies of the (not especially attractive) principals. The crudity of the title, suggesting the availability of secretaries discovering their inner whore, celebrates turning the most mundane environment into an erotic playground. Real Hardcore Auditions Reel 1 Vol. 1 (2010) positively revels in its amateurism as it presents three cursory scenes dramatising the auditions (an audition is a standard porn scenario) of three types, the 'Chav Slut', the 'Porn Star' and the 'Housewife'. The 'Chav Slut' is Sarah, twenty-three, married, in tight clothes with her hair pulled back in a 'Croydon face-lift' and a massive scorpion tattoo on her arm. Enhancing the unmediated sense of documentary performance, a stills camera flashes throughout as Sarah demonstrates her understanding of the requirements of porn - a blow job, cunnilingus, sex from three positions, and finally a facial 'popshot' . The film's intention is, as Morgan says, to 'let the girls be themselves and as natural as possible' (personal communication), while the depiction of these stereotypes is rich in cultural resonance, drawing on the 'sluttish' implications of tattoos, piercings and shaved genitalia, which imply an easy, sexualised working class. 
Another down-market film, which directly relates porn to the wider economics of sex work, is the Real Punting series that has been running since 2004, in which an ordinary looking Joe (usually Jay Kennedy) has sex with what purport to be real escorts and prostitutes. The scenes include the exchange of money, discussions of limits and what acts (kissing, anal sex) are permitted. The porn shoot, which is never realistic in the sense that, say, erectile failure might be included, becomes the record of a staged business encounter. As well as neatly securing the identification of porn actors with prostitutes, the films are also, inevitably, spin-offs and advertisements for Kennedy's website, www.realpunting.com, where many of the DVDs' sequences originated and where 'you can also then contact the Escort you just watched get fucked and book your own private session with her'.

None of this, of course, is especially defensible - and I suspect that is precisely the point. As an escape from respectability, political correctness, and normative definitions of sexuality, hardcore in Britain has grabbed the cultural space offered to it as filthy, extreme, and Other, which in Britain is co-extensive with the sexuality of working class women and the tastes of working class men. The packaging of some of the DVDs consequently flaunts a cheap and amateurish look that is not only economically driven but designed to promote the content as authentically sleazy. For example, the Freddie's British Sluts series (also known under various other titles such as Fat Freddie's English Fuckers) presents its poor quality films in very basic packaging, but, as with Real Hardcore Auditions, their appeal is enhanced by their homemade unpretentiousness and 'realism'.

Some British producers do appeal to 'classiness', as with Film Erotica's The Estate Agent (2006), The Beach (2008), Garden of England (2010), and The River Cottage (2010). With chaste front covers (a picture of a red door for The Estate Agent, 
a bitten apple for Garden of England), the films promise 'first timers', location shooting and, instead of urban grittiness, fantasies of middle class rural escape. Harmony's Young Harlots: The Academy (2006), on the other hand, like rest of this series directed by Gazzman, is much closer to the edgy hardness of American porn or Marc Dorcel's Russian Institute films (since 2005). The Young Harlots series is a variation of the school sub-genre. Explicitly Sadean, its discourse of 'training', popularised by Rocco Siffredi, extends l'éducation des senses to the 'breaking in' of female actors so that they become pliable adepts at pornographic performance. Gazzman's Sodomized Sluts (2010), similarly, despite its continental European male actors, is US-style in its cursory set-ups, sharp-edged photography, upmarket interiors, flatly filmed close ups for maximum visibility, lack of atmosphere, and focus on 'acts' such as anal sex, deep throat, gaping, A2M (ass to mouth: the penis goes from the woman's anus to her mouth in one unbroken camera shot), face-slapping and the use of a speculum. To prove that British porn can be as 'hard' as its continental and American rivals, women's bodies are shown in extremis as both receptacle and toy. This is 'realism' in a different and, one might say, international sense - porn as a record of exhausting bodily labour, engaged in by professionals with special skills and tolerances.

While the films' presentation of material may seem excessive and 'boring', they are information-rich in unmediated physical detail. If we can get beyond the demonization of 'the gaze' as sadistic objectification, watching porn can be understood in terms of intense looking (and listening), curiosity, fascination, boundary-challenging and even aesthetic appreciation (heightened, as with much low culture, by bodily engagement rather than by intellectual detachment) (Hunter 2012). The gynaecological overkill critics often recoil from and the brute depiction of bodies 
as just stuff, meat in motion, are intrinsic to the genre's unsettling fascination. Trends of the 2000s, for example, highlight intimate un-squeamish emphasis on the eroticisation of abjectly messy imagery such as the expulsion of semen from vaginas and anuses ('cream pies'), deep throat 'gagging' (sometimes to the point of vomiting, though that always falls foul of the BBFC), women 'squirting', and hyperbolic variations on facial 'cumshots' such as 'bukkake', a Japanese-derived sub-genre of multiple ejaculations on a woman's face. These trends, whose extremes are moderated by the BBFC, can certainly be seen as intensely misogynistic and brutalising, depicting things not only generally unseen but regarded as degrading, repulsive and infantile; in short, abject (Paasonen 2011: $207-49){ }^{2}$ They challenge taboos about the body, its fluids, and the erotic possibilities of pushing the limits of corporeal tolerance, and the films can seem more like demented outtakes from Jackass: The Movie (2002) than conventional masturbation fodder.

\section{Ben Dover and Anna Span}

The straight porn film can be seen as a sort of ideal porn super-text in which all the genre's key elements are gathered in abstract allegories of gender relations, reducible perhaps to repeated identical tableaux of unchanging male oppression. An essentialist view of pornography, combined with inattention to its production contexts, textual specificity and variety of uses, means that, as Clarissa Smith argues, 'pornography suffers from a surfeit of contempt that manifests itself in characterizations of the category's homogeneity and ... the uniformity of possible responses to, or expectations of, its subsets' (Smith 2005: 148). One might therefore wonder how a degree of individuality and even personality could be imparted to a genre so dedicated to just showing. Lindsay Honey and Anna Span nevertheless, within strict generic 
formulae, attempt to differentiate their films from the mass of production, not least by topping and tailing, as it were, lengthy sex scenes with set-ups enriched by dialogue that gives an everyday ambience to the events.

Honey is the most high-profile contemporary British porn director and 'the Mike Leigh of porn' (Brent 2003: 80). His films, which he directs as Steve Perry and stars in as Ben Dover, combine up to date technology and the latest innovations in porn with, from a British angle, a certain degree of nostalgia, though his films were exported very successfully to the US. In the 2006 BBFC report, while Private was the most popular label, 'Ben Dover is the $2^{\text {nd }}$ most popular production house for heterosexual product, with $10 \%$ of females and 5\% of males [preferring Dover's films]' (BBFC 2006). At once laddish chancer, disbelieving the sexual possibilities that come his way, and creepy groomer of a traditional cast of horny housewives and randy secretaries, Ben Dover updates the working class conspicuous sexual consumption of 1970s sexploitation icons such as Robin Askwith of the Confessions series. His persona also incorporates an upwardly mobile Thatcherite element, with porn his chosen route to wealth (nice watches, flash cars) through entrepreneurial industry. His films are typified by

slutty looking girls who aren't quite as attractive as some of the foreign crumpet you'll see shagging for money, but who are always wet and willing. All of this combined with some dirty, dirty shagging scenes and Ben’s usual comedy chit-chat, which the Yanks love, but you might end up hating after 150 minutes (Knave 2001: 102). 
Honey started to make films on video for Mike Freeman’s Videx from 1979 to 1982 - when the company was closed down in a police raid - while hardcore was still illegal in Britain and its production a small-scale cottage industry sold through ads in video magazines. Honey, whom Freeman had contacted through Stage, was one of Freeman's regular actors but while Freeman was in jail for obscenity charges he started up on his own, using Videx’s equipment and mailing list (Porter 2010: 18). In the 1980s he and his partner, Linzi Drew, sold tapes through a mail order business, for which they were imprisoned in 1992 (Drew 1993: 154ff). The Ben Dover films, which began in 1996, are gonzo movies with an emphasis on real girls and anal sex (an act illegal for heterosexuals in Britain till 2000). Gonzo is a style of porn that began with John Stagliano (Buttman) in The Adventures of Buttman in 1989, in which the cameraman participates in the action and comments on it in real time. The pseudodocumentary approach emphasises reality and immediacy, mixes professionals and amateurs ('pro-am'), and situations the sex within a barebones narrative or storyline. Dover traces the style back to Freeman, who 'really invented gonzo porn without even knowing it’ (Honey in Bryce 2009: 76): ‘there’s an interesting squaring of the circle with Mike Freeman. He was kind of doing back then what we're doing now, not even pretending that the camera's not there or anything. His videos had that amateur, madeup-as-you-go-along feel’ (Honey in Brent 2003: 78). (Freeman himself demurs: ‘I never made Gonzo, my films had a strong storyline, a beginning middle and an end' (personal communication May 2012).)

The early Ben Dover films involved Ben and his recurring cast of actors (including over the years Omar, Pascal White - a stringy 'Bouncing Belgian’ - and Super Mario) picking up girls or turning up at 'real' housewives' houses in answer to their sexual fantasies. Dover's intention was to ‘completely go against the American 
system and turn the whole thing on its head - no makeup artists, no fancy costumes or locations - just a bunch of people having a laugh' - humour is crucial to his approach (author interview 1 May 2012). Because he ‘discarded the porn rules’, some distributors thought his first films seemed unedited, but he wanted to make the kind of porn film he wanted to watch, which meant a long build up, 'a lot of teasing' and a scenario where 'the girl is talked into it' (author interview). Ben does most of the camerawork, and usually receives blow jobs before providing the final shot of ejaculation. According to Honey, the films in which it all came together for him were The XXX Factor (2005) and The XXX Factor 2: The Next Level [US title: Ben Dover's Kick Ass Adventures 5] (2005), which featured 'massively long builds up shot in secret', 'the girls were all hot' and he started to 'turn the corner and become more hardcore and push the boundaries'.

The most recent Ben Dover films are made for Bluebird, a British company owned by Paul Baxendale-Walker, who bought Loaded in 2012. The films are less focused on pick-ups now (real pick-ups being impossible because condoms and HIV testing would now be required beforehand) but still 'specialize in sort of new, newish girls' and sequences continue to run long ('about 25 - 30 minutes, which is the same length as a television sitcom' (Anon 2004)). Though Ben retains his enthusiastic, everastonished persona throughout, Honey describes himself as having sold out in his new films because they emulate the directness of American porn and drop the elaborately teasing build up. Another change, and part of the deal with the distribution company, is that he now joins in the sex, it having eventually 'freaked people out' that he just masturbated on the girls. For financial motives and because, having split from his long term partner, Linzi Drew, he is now single and ‘there was no reason not to’, Honey now participates fully in the sexual action and only occasional cuts to a 'Ben- 
cam' view link the films back to his original innovative format. His latest series, Like Father, Like Son (2012), moves with the times - he plays an older man on the prowl with his son because the 'the dynamic has slightly changed' - the fantasy is now an older man and the younger woman and it is essential 'to see him dominating her that's the way it is' (author interview). But, though he agrees that porn has got more extreme over the years in its desire to 'push limits', he has tried to keep what he calls ‘the cheeky chappie’ persona.

One of Dover's most characteristic films is Fancy an Indian? (2003), a compilation DVD whose scenes of sex with ‘Asian’ women typify his unusually expansive and conversational style. The film combines racial and food imagery in presenting the women as exotic meals, highlighted in explicitly racist language in online adverts: 'Well, goodness gracious me! On the menu today are five deliciously spicy dishes, all Indian, and all hot and ready to go'. The documentary format affords the pretence that Ben is exploring different cultures, typified by repression and hypocrisy, with sex as 'important for Anglo-Indian relations', as Ben puts it at one point.

The film is explicitly tailored for domestic consumption - it is small scale, intimate, and designed for viewing at length. The amount of time spent establishing each set-up is characteristic of Dover's approach. Porn DVDs are long nowadays - up to three hours is standard - and viewers with remote controls can direct the speed of the action to find the appropriate moment. While the cinema mainstream has moved towards what David Bordwell calls ‘intensified continuity’ (Bordwell 2002) - notably fast-cutting - porn has gone in the other direction and shifted towards very long observational shots and sequences that take their cue from amateur film-making and 
are made possible by filming extended takes on digital video. Porn is 'intensified' by a style favouring duration, repetition, and the clarity of pin-sharp close-ups.

In Fancy an Indian? the extensive set-ups concretise the situation in a spirit of realism and individuation that both enhances the documentary aspect and makes the final sex scenes more transgressive as the women are garrulously 'seduced' into stripping and engaging in racially-charged 'forbidden' sexual activity. As with most Ben Dover films dialogue - or more accurately, Ben's monologue - is important, as he admires in expostulations of delight and rapture the woman's exposed and opened body. The film's eroticism is predicated on the seemingly unmediated depiction of sexual pleasure and the breakdown between documentary and performance to create a coherent spectacle sufficiently enthralling to speak to and complement viewers' fantasies. In Fancy an Indian? the objectification of bodies, the stripping of cultural markers, the animalistic reduction, if you like, of Western and Eastern bodies to genitals, fluids (two sequences end with the woman urinating), and acts, are its attempt at liberation. There is a sense, at any rate, of mutual enjoyment and sex for its own sake, and, most important, a consistent theme of introducing the women to new experiences - notably anal sex.

This eroticisation of persuasion led to the BBFC cutting short the final sequence of Fancy an Indian, a disturbing sequence in which Ben is fellated by Geeta Kara, an unenthusiastic young woman, which features, according to the BBFC website, 'elements of coercion and lack of full consent'. (It is unclear whether this means the BBFC thought the actress was coerced or whether they objected to the dramatised eroticisation of coercion.) At this point the extratextual - the realities of onset performance rather than realism of style - makes a painful intrusion into the 
diegesis, and insight into the working conditions endured for the sake of 'naughtiness' opens up questions about consent and exploitation that the film cannot contain. ${ }^{3}$

While the Ben Dover films (pace the BBFC report) might be regarded as intrinsically male-orientated, Anna Span (Anna Arrowsmith) promotes herself as the 'first British female porn director'. She has carved out a career making female friendly sex films, though they are generally not marketed specifically to women. Rather they have what she calls ‘a woman’s point of view’. Although initially antiporn, Span says that she realised her hostility was as much to do with jealousy as anger and this spurred her to make porn that might reflect women's fantasies.

Over the last 14 years I have filmed graduates, university students, ex-lawyers and photographers. The work offers a highly paid and exciting alternative to the tedious monotony of many other jobs. Anti-porn campaigners find it impossible to accept that young people might dream of shagging good-looking people on camera, showing off their bodies and accessing a huge adoring fan base that sometimes shower the stars with gifts (Arrowsmith 2012).

At first sight the films released on her Easy on the Eye label seem little different from standard porn, at any rate structurally and in terms of the acts shown. The films are divided into vignettes on one theme; each is about eighteen minutes long, and heterosexual scenes generally include the usual progression from oral to sex to visible ejaculation and 'facials', which Span disagrees are necessarily sexist. The 'woman’s point of view' is reflected in, first, the women being, perhaps, more ordinary than is typical and the men notably better looking, with the kind of toned bodies more usually visible in American gay porn; and, second, in ensuring that 'one 
in three shots is looking at the man' (author interview 7 November 2011). A relative lack of sleaziness might also be considered woman-friendly, as there is some evidence that women view sexual material more aesthetically than men do and find it difficult to believe that 'real wives' could be found attractive (Attwood 2005: 75). The films also include more oral sex and foreplay than usual, keep to three or so positions, and emphasise eye contact.

Gender aside, Span regards the Britishness of her films as important. Most are set in recognisable London locations such as Hoxton (Hoxton Honey (2005)), Bermondsey (Hug a Hoodie (2007)), and Notting Hill (Notting Hill Honeys, a series for the satellite channel Television X, where her first porn venture, Eat Me/Keep Me was shown in 1999 and which subsequently showed versions of her films later released on DVD in R18 cuts). Initially the films' realism drew on her own background as a film student at St Martin's and include recognisable details of life among the art school crowd in trendy areas. Hug a Hoodie, equally observational, is about multiracial pairings of 'chavs'. Her films are what she calls 'soap opera with sex in it' (author interview). In fact, to ensure verisimilitude and authenticity, the uniforms in A \& O Department (2005) and Hand of the Law (2006) were supplied by the same outfitters used by The Bill. There is an attempt at accurate casting, with women in believable roles and an attempt to 'incorporate fantasy and reality together' by eroticising everyday life. The effect aimed at is 'day-dreaming in real life' on the assumption that women like 'quality'.

Their realism is influenced by the early Ben Dover, who took time to set-up a believable situation before the sex commenced, as well as the semi-documentary casualness of films such as Flesh (1968) and Trash (1970) and later American independent cinema. Porn, according to Arrowsmith, has a link with experimental 
film-making in that sex is 'a live dance you have to catch' and the best way is improvisation within a framework rather than a fully-worked out script; it is perhaps closer to performance art than to conventional acting. Talk is important, as it is in Ben Dover films. Play the Slut (2008), for example, includes a good deal of naturalistic dialogue in the build up to its 'lesbian' sex scenes. But she is also influenced by the medium framings and kitchen sink style of 1970s television, as well as its humour, though there is no humour once the sex starts. Nevertheless for all the film's 'realism' the sex is emphatically a pornographic performance rather than an attempt (as with 9 Songs, which she advised) to document sexual behaviour accurately, and so Span has what she calls the 'five into two' rule. As three of the five senses are not accessible by film, the other two must be heightened to compensate. Sex noises are exaggerated and filming thus accentuates the visible angles of the body.

Though Span's milieu includes both bohemian and 'chav' London, her aim is still to create, in the 'Readers Wives' tradition, accessible, downmarket and thoroughly dirty fantasies of sexed-up everyday working class life. This ties her films, like Dover's, to softcore films of the 1970s, top shelf magazines and other manifestations of working class naughtiness that seem as British as the alleged and proverbially bizarre fetishes of German porn, the pixillated specialisms of Japanese porn, and the pneumatic fakery of American.

\section{Beyond the sex shop}

Today the production and consumption of porn films as films is something of an anomaly. In a sense it always was, if by film one means something other than a fifteen to twenty minute sequence; in sex cinemas the audience pays - or rather paid, for such cinemas are now fairly uncommon - for entry to the homoerotic cruising space of the 
auditorium itself rather than to see a particular film. Indeed compilations of discrete scenes and the experience of entering a pornographic space have always been more central to porn than the single narrative. As Laurence O’Toole points out:

Watching porn like you're watching mainstream cinema won’t much help you tune in to what porn is truly about, and will probably leave you thinking that porn is cheap, lowbrow, not very good art, and all the other put-downs that have launched a thousand mainstream magazine articles on the subject (O’Toole 1999: 85).

Watching a porn DVD these days is almost an exercise in nostalgia, for it implies pornography is defined as a bounded singular text rather than as an embedded fragment alighted upon during an endless dérive across multiple sites in search of a version of what Barthes called the 'punctum' - a 'detail that overwhelms the entirety of my reading; it is an intense mutation of my interest, a fulguration’ (Barthes 1984: 49). In pornography it may be the shot, act, sequence or raw image that precisely matches one's personal fetish and gears smoothly into the combination of memory, fantasy and anticipation that satisfies desire. The notion of $a$ pornographic text seems outmoded as opposed to an experience of the pornographic in a newly obscene domestic realm of infinite online pornographies. I suspect we need an expanded definition of textual consumption to make sense of how people relate to porn, since formal analyses of porn films, let alone the largely descriptive efforts in this article, don't give much sense either of how they circulate in cultural and social life. As Laura Kipnis has said, ‘Pornography isn’t viewed as having complexity, because its audience isn’t viewed as having complexity’ (Kipnis 1999: 177), and the most 
welcome shift in research is away from 'media effects' models and towards qualitative studies of audiences’ uses of pornographies (Smith et al 2012).

In the age of the internet, purchases of R18 DVDs from sex shops are a minor aspect of porn consumption in Britain. In the 2006 BBFC report shops were not the main source even of DVDs. While $51 \%$ of respondents got a new sex video or DVD from a friend or relative, only $41 \%$ got them from a licensed sex shop. $36 \%$ used mail order/internet and 15\% got them from abroad (BBFC 2006). It is reasonable to assume that porn consumption in the twenty first century happens mostly online, by clicking through to the innumerable clips of professionally produced and amateur footage uploaded, often in defiance of copyright, to freesites. Accessing the pornographic blurs with premium rate phone chat lines which developed after 2001 such as Babestation (from 2002), magazines, cable and satellite TV channels and other engagements with commercialised erotic representation.

The relationship of the consumer to porn has therefore changed radically from the 1980s. Instead of a nerve-wracking detour to a sex shop or sex cinema, or handedround copies of illegal videos, there is now a casual relationship of indifferent but compulsive browsing, a parody of the unending and unsatisfiable pursuit of novelty and fulfilment's desolate attic, as Larkin put it, that characterises consumer capitalism. The primal scene of encountering porn is no longer coming across a male relative's stash, but rather Googling without safe search, an experience rather like the seamless 'flow' of TV: 'the user must keep seeking through the screen the ultimate twodimensional image in an endless enactment of desire, a fractured and dispersed hypertextual narrative’ (Reading 2005: 128). This easy yet distanciated engagement with decontextualised images of sex is arguably new. Consequently, anxiety is not caused by any particular film or generic trend, but rather with pornography itself, 
identified now entirely with the internet and accompanied by a flat assertion that, in its most visible strands, porn is becoming more intensely violent, explicit and misogynist:

Images today have become so extreme that what used to be hardcore is now mainstream pornography. Rather than sporadic trips into a world of coy smiles, provocative poses and glimpses of semi-shaved female genitalia, youth today are catapulted into a world of ravaged anuses, distended vaginas and semen-smeared faces (Dines 2010: xvii).

Countering this, a new wave of anti-porn feminism has emerged in the US and the UK to revive the 'porn wars' of the 1980s (Long 2012). They pursue a campaign against the encroaching 'pornification' of British culture - the migration of porn from the margin to the mainstream. This is the most significant current discourse about porn, whose boundaries stretch to include such evidence of pornographic drift as 'lads's mags', Page 3 of The Sun, labiaplasty, pubic shaving, cosmetic surgery, and women's willing self-objectification as lap- and pole-dancers. There is an apocalyptic sense, shared on the right and radical feminist left, that, as Robert Jensen puts it, 'Pornography is what the end of the world looks like': 'pornography encourages men to abandon empathy, and a world without empathy is a world without hope' (Jensen 2011). Concern about pornographic content is difficult to disentangle here from anxieties about the internet itself, masturbation (by men, whose sexuality, in a 'rape culture', is intrinsically suspect) and the addictiveness of consumer capitalism, of which pornography can be seen as the purest product. Porn films, even the most celebrated such as Deep Throat (1972), are not so much films, from this cautionary 
perspective, as documentaries of abuse and exploitation, evidence of real-world harm rather than representations of sexual performance. The proper context of porn, you might conclude, is not cinema at all but other closely related kinds of economicallyinduced sex work under patriarchy, such as prostitution, trafficking, sex phone lines, stripping, peepshows and lap-dancing.

As for British porn production, both Span and Honey are pessimistic about the industry’s future on R18 DVDs. There is, Honey says, no market for DVDs anymore; everything has shifted to the internet, where because of piracy and free sites, professional pornographers are at a disadvantage: 'Most companies,' he claims, 'are going bust - legalisation meant the destruction of the legitimate industry' (author interview). Cable too, he says, is 'dead in the water', while even Playboy's profits come mostly from T shirts and pencil cases and Vivid's and Hustler's from their nightclubs. Pornification, according to Britain's most famous pornographer, was the death knell of the industry, and he, for one, wishes he had never campaigned for legalisation. Before then, he says, sounding like a British horror fan nostalgic for the days of 'pre-cert' video, 'it was exciting and fun'.

Overshadowed by the internet, the R18 remains a rarely discussed aspect of porn production and consumption, pre-vetted, certificated, strictly controlled but, in a very British compromise, hidden away in plain sight in sex shops. Few of the recent media reports about pornification have challenged or even seriously considered this entirely legal market for hardcore. Although DVD is increasingly a 'heritage' medium, it is just plausible that R18 consumption may revive as online access to porn is further monitored and restricted. The time will doubtless arrive when the abolition of the R18 will be debated. But for now the R18 is a place where a distinctive style of British pornography endures, the product of a culture both repressed and bawdy, 
where porn is associated with the wickedness of 'Europe' across the Channel or with the USA, and where sex is constructed as naughty, dirty and intrinsically comic.

\section{Acknowledgements}

My thanks to Ben Dover (www.bendover.com), Anna Arrowsmith and Poppy Morgan for granting interviews and to Feona Attwood, Clarissa Smith and Sarah Harman for invaluable advice on earlier drafts of this article.

\section{References}

Anon (2004), 'Ben Dover: he’s back in the U.S. market via Kick Ass Pictures', AVN

Insider 8 November, available at: http://www.avinsider.com/stories/lead110804.shtml. Anthony, Sebastian (2012), 'Just how big are porn sites?’, Extreme Tech 4 April, available at: http://www.extremetech.com/computing/123929-just-how-big-are-porn$\underline{\text { sites/2. }}$.

Arrowsmith, Anna (2012), 'What's all the fuss about the “feminist” porn star James Deen?', The Guardian 20 March, available at: http://www.guardian.co.uk/commentisfree/2012/mar/20/james-deen-feminist-pornstar.

Attwood, Feona (2002), 'Reading porn: the paradigm shift in pornography research', Sexualities 5: 1, pp. 91-105.

Attwood, Feona (2005), 'What do people do with porn? Qualitative research into the consumption, use, and experience of pornography and other sexually explicit media' Sexuality \& Culture, 9: 2, pp. 65-86.

Barthes, Roland (1984), Camera Lucida: Reflections on Photography, trans. Richard Howard, London: Flamingo. 
BBFC (British Board of Film Classification) (2006), The Use of Sex Videos and DVDs in Britain: Summary of Findings of the BBFC Research, London: British Board of Film Classification, available at:

http://www.bbfc.co.uk/sites/default/files/attachments/Research\%20into\%20the\%20us e\%20of\%20pornography_0.pdf

Brent, Andy (2003), 'Dover and out!’, DVD World August. Publisher?

Bryce, Allan (2009), 'Ben behaving badly’, DVD World 71.

Chalabi, Mona (2012), 'Porn: what we know, what we don't', available at:

http://www.guardian.co.uk/news/datablog/2013/may/24/missing-statistics-

pornography

Dines, Gail (2010), Pornland: How Porn Has Hijacked Our Sexuality, Boston:

Beacon Press.

Drew, Linzi (1993), Try Everything Once Except...Incest and Morris Dancing, London: Blake.

Fountain, Tim (2008), Rude Britannia: One Man’s Journey Around the Highways and Bi- Ways of British Sex, London: Weidenfeld \& Nicholson, 2008.

Foxton, Willard (2013), 'The problem with the 'debate' over online porn is the two sides aren't even speaking the same language', The Telegraph, available at: http://blogs.telegraph.co.uk/technology/willardfoxton2/100009299/the-problem-with$\underline{\text { the-debate-over-online-porn-is-the-two-sides-arent-even-speaking-the-same-language/ }}$ Green, Jonathon (1993), It: Sex Since the Sixties, London: Secker \& Warburg. Hayes, Michael (2006), 'Britain leads the way in online porn’, XBIZ 30 May, available at: http://www.xbiz.com/news/15216. Hunt, Leon (1998), British Low Culture, London and New York: Routledge. 
Hunter, I.Q. (2012), ‘A Clockwork Orgy: a user’s guide’ in Mendik, Xavier (ed.), Peep Shows: Cult Film and the Cine-Erotic, London and New York: Wallflower Press, 2012, pp. $126-34$.

Hunter, I.Q. (2013), British Trash Cinema, London: BFI/Palgrave.

Jenson, Robert (2011), 'Pornography is what the end of the world looks like', available at: http://goodmenproject.com/featured-content/pornography-is-what-theend-of-the-world-looks-like/

Kipnis, Laura (1999), Bound and Gagged: Pornography and the Politics of Fantasy in America, Durham: Duke University Press, 1999.

Knave Video Special 1 (2001).

Long, Julia (2012), Anti-Porn: The Resurgence of Anti-Pornography Feminism, London: Zed Books.

Mackay, Finn (2011) ‘A movement of their own: voices of young feminist activists in the London Feminist Network', Interface: A Journal for and about Social Movements 3.2: $152-179$.

Ministry of Truth (2013) 'Sex, lies and porn statistics’, available at: http://www.ministryoftruth.me.uk/2013/06/18/sex-lies-and-pornstatistics/?utm_source=rss\&utm_medium=rss\&utm_campaign=sex-lies-and-porn$\underline{\text { statistics. }}$

O’Toole, Laurence (1999), Pornocopia: Porn, Sex, Technology and Desire, $2^{\text {nd }}$ rev. ed., London: Serpent’s Tail.

Paasonen, Susanna (2011), Carnal Resonance: Affect and Online Pornography, Cambridge, MA, and London: MIT Press. 
Paasonen, Susanna (2012), ' 'Homespun: Finnporn and the meanings of the local', in Hines, Claire, and Kerr, Darren (eds), Hard to Swallow: Hard-core Pornography on Screen, London and New York: Wallflower Press, pp. 177-93.

Petley, Julian (2000), 'The censor and the state', Journal of Popular British Cinema 3, pp. $93-103$.

Petley, Julian (2013), '”The following content is not acceptable”’, in Attwood, Feona, Campbell, Vincent, Hunter, I.Q., and Lockyer, Sharon (eds), Controversial Images: Media Representations at the Edge, London and New York: Palgave Macmillan, pp. 131-53.

Porter, Ric (2010), Welcome to Pornoland, Woodford Green: Portway Books.

Reading, Anna (2005), 'Professing porn or obscene browsing? On proper distance in the university classroom', Media, Culture and Society, 27: 1, pp. 123-30.

Ropelato, Jerry (2012), 'Internet pornography statistics', TopTenREVIEWS, available at: http://internet-filter-review.toptenreviews.com/internet-pornographystatistics.html.

Smith, Clarissa (2005), ‘A perfectly British business: stagnation, continuities, and change on the top shelf', in Sigel, Lisa Z. (ed.), International Exposure: Perspectives on Modern European Pornography 1800 - 2000, New Brunswick: Rutgers University Press, pp. 146-72.

Smith, Clarissa (2012), 'Reel intercourse: doing sex on camera’, in Hines, Claire and Kerr, Darren (eds), Hard to Swallow: Hard-Core Pornography on Screen, New York: Columbia University Press, pp. 194-214.

Smith, Clarissa, Attwood, Feona, and Barker, Martin (2012), Pornresearch.org: Preliminary findings, http://www.pornresearch.org/Firstsummaryforwebsite.pdf 
Williams, Linda (1991), Hardcore: Power, Pleasure and 'The Frenzy of the Visible', London: Pandora.

\section{Notes}

${ }^{1}$ This article is about straight R18 rated legitimate British hardcore porn. I don’t know nearly enough about gay porn to comment on it, and it rarely features anyway in recent discussion of pornography, which is invariably framed in relation to sex work and violence against women.

2 The overlap between porn and 'body horror' can be experienced on 'extreme' shock websites like Heavy-R, whose servers are based in the Netherlands but which is reported to be most popular in the UK. Search categories on Heavy-R embrace not only pornography, much of it illegal in R18s ('Anal Prolapse', 'Anorexic', 'Puke’, 'Scat'), but reality footage labelled 'Disgusting', 'Execution' and 'Traffic Accident'. See: http://www.freewebsitereport.org/www.heavy-r.com.

${ }^{3}$ The sequence can be streamed here: http://t.hardsextube.com/video/1092836/BenDover-Fancy-An-Indian-Geeta-Kara. 